\title{
COMPARISON OF THE MEASUREMENT RESULTS OF LARGE SCALE FAÇADE FIRE TESTS USING IR THERMOGRAPHY AND THERMOCOUPLES
}

\author{
Bojan Milovanović, Ivana Banjad Pečur \\ University of Zagreb, Faculty of Civil Engineering, Zagreb, Croatia
}

\begin{abstract}
In this paper the effectiveness of using a high temperature range, microbolometer infrared (IR) camera for the study of large scale façade fire tests will be investigated. The long-wave microbolometer camera has the ability to measure temperatures but the smoke and the flames itself influence the measurement results. This is due to the absorption of the infrared radiation by both smoke and flames while at the same time they emit radiation due to their high temperatures. The purpose of this study is to demonstrate the usefulness of an IR camera when studying large scale façade fire tests. The problems are difficulties in verification how representative measurements are and consequently it is not clear and sure if conditions for reliable measurements are really fulfilled. The measurement results acquired by the IR camera will be compared to the measurement results acquired by the thermocouples $1 \mathrm{~mm}, 3 \mathrm{~mm}$ in diameter and plate thermometers.
\end{abstract}

Keywords: Infrared thermography; fire test; smoke; flames; emissivity;

\section{INTRODUCTION}

Thermography is a type of imaging that is accomplished with an infrared (IR) camera calibrated to display temperature values across an object or scene. Therefore, thermography allows one to make non-contact measurements of an object's temperature. The IR method provides sequences of 2D temperature maps of the testing specimens during the whole test, with no need of previous sample preparation, in a non-intrusive way, and with good time resolution.

On the other hand, fire is a rapidly changing, high temperature phenomenon inhomogeneous in space, and therefore fast, remote, 2-D measurements are particularly useful in fire studies. IR imaging has become a common technique, for instance, in the study of forest fires (Meléndez et al., 2006). However, it faces difficulties when it comes to providing quantitative temperatures in fire environments. Therefore, when imaging a flame the temperature readout of an IR camera is not indicative of the real object temperature and should be compensated. The flame gases have a transmittance (and therefore, emissivity) that is generally unknown and depends on concentration and has strong spectral features. Hot gases emit radiation in particular bands of the infrared spectrum. The highest emission of $\mathrm{CO}_{2}$ is located at $2.7 \mu \mathrm{m}$ and $4.4 \mu \mathrm{m}$ and the maximums of $\mathrm{H}_{2} \mathrm{O}$ are at $1.4 \mu \mathrm{m}, 1.9 \mu \mathrm{m}$ and $2.7 \mu \mathrm{m}$. However, soot particles emit radiation in a continuous spectrum over a wider region from the visible to the infrared, and the more the wavelength increases, the greater the drop in radiation intensity (Sato et al., 1969). Nevertheless, this reduction in intensity is omitted by the majority of authors (Draysdale, 1997); according to their approach, soot particles and flames generally are considered to be grey or black bodies. Within a flame, these soot particles attain high temperatures and each one acts as a minute black or grey body. It is well known that emission from the soot particles is much larger than emission from the molecular emitters, such as $\mathrm{H}_{2} \mathrm{O}$ and $\mathrm{CO}_{2}$. It was found that the non-luminous methanol flame has an average temperature of $1200{ }^{\circ} \mathrm{C}$, while the luminous flames of kerosene and benzene were much cooler, $990{ }^{\circ} \mathrm{C}$ and $921{ }^{\circ} \mathrm{C}$ respectively (Jiang, 1995), generally speaking, the "sootier" the flame, the lower its average temperature. Thus, to a great extent, flame radiation and temperature depends on the flame sootiness because of the heat loss mechanism. 
The first attempts of using IR thermography to measure the temperature of a solid wall viewed through a flame used a spectral region $(10.6 \pm 0.5 \mu \mathrm{m})$ where the emission from $\mathrm{CO}_{2}$ and $\mathrm{H}_{2} \mathrm{O}$ is negligible, and, for thin flames, soot emission can be also neglected (Arakawa et al., 1993). However, this is not true for other experimental conditions, and a procedure to discount flame contribution must be established. (Meléndez et al., 2010) proposed a thermographic method to measure temperatures of solid surfaces subject to a fire, which accounts for the flame contribution with no need for specific sample preparation. A "flame image" is obtained and then subtracted from the scene image to obtain a corrected image which is an approximation to the radiance emitted by the solid phase, and which can be translated into an instantaneous temperature map of the surface.

Flame radiation intensity depends on its composition and on the concentration of its molecules along its optical path. Although an infrared active material has discrete characteristic wavelengths which represents the motion of the molecule structure, soot emits and absorbs continuous thermal radiation in the infrared region. What can be gathered from this is that flame emissivity is strongly conditioned by its thickness, by its regime and conditions of combustion and by the composition and the type of fuel burned. With an efficient mixture of fuel and air, soot production is minimal and a less radiant and bluish flame appears, with very high temperatures (Pastor et al., 2002). Flames from the combustion of methanol with an emissivity of 0.07 reach an average temperature of $1200^{\circ} \mathrm{C}$ (Rasbash et al., 1956). However, incomplete combustion, due to a defective mixture of fuel and comburent or due to a lack of comburent, causes the formation of small particles of carbon, which make up soot and produce yellowish and orangish flame which have very high emissivity but a lower temperature. In (Quian and Saito, 1995), hexane flames of $20 \mathrm{~cm}$ of thickness reached emissivity values of about 0.8 with mean temperatures between $700{ }^{\circ} \mathrm{C}$ and $800{ }^{\circ} \mathrm{C}$, and it was also determined that with larger the diameter of pool fire, the emissivity was higher, while the transmissivity was lower. Also, a progressive increase in emissivity with the diameter of the flame in laminar and transition regime was demonstrated. (Chatris, 2002) tested with greater thicknesses, up to $50 \mathrm{~cm}$, which were representative of the turbulent regime. This author obtained emissivity values of around 0.85 from gasoline and diesel flames, and maximum temperatures of around 750 ${ }^{\circ} \mathrm{C}$. In (Hägglund and Persson, 1976), flame thickness ranged from $15 \mathrm{~cm}$ for smaller fires to 200 $\mathrm{cm}$ for larger ones. Temperature varied between $650{ }^{\circ} \mathrm{C}$ and $1030{ }^{\circ} \mathrm{C}$, while calculated emissivities reached values close to unity in some tests, ranging between 0.12 and 0.94 . (de Vries et al., 2015) showed that the effect of the flames present between the surfaces of interest and the IR camera only contribute to about $50 \mathrm{~K}$ increase in measured temperature due to the limited flame emissive power with low soot concentration in the long-wave IR regime. Based on the spectral transmissivity (Du et al., 2012) investigated the flame emissivities under different air/waste equivalence ratios where effective emissivity changed from 0.80 to 0.89 , with lower the emissivity when more air was added. (Pastor et al., 2002) showed the relationship of emissivity values and flame thickness for flames of forest fires, where he compared experimental results of emissivity measurements with the expressions mentioned in literature. This research showed that emissivity of a $1.0 \mathrm{~m}$ thick flame is between 0.8 and 0.7 , measured at $1 / 4$ and $3 / 4$ of the total flame height, respectively, while the models showed in the same paper predict the emissivity above 0.90 for flame thickness' above $1.0 \mathrm{~m}$.

\section{EXPERIMENTAL SETUP}

All infrared images were acquired using an uncooled FLIR ${ }^{\circledR}$ P640 microbolometer. This camera has a 640x480-pixel uncooled microbolometer thermal detector sensitive at wavelengths between $7.5 \mu \mathrm{m}$ and $13 \mu \mathrm{m}$. The field of view (FOV) of the lens is $24^{\circ} \times 18^{\circ}$, providing a 0.65 mrad spatial resolution. The maximum (full) frame rate of this camera is $30 \mathrm{~Hz}$. The P640 LWIR camera has a factory pre-calibrated object temperature range of $-40^{\circ} \mathrm{C}$ to $120{ }^{\circ} \mathrm{C}, 0{ }^{\circ} \mathrm{C}$ to $500{ }^{\circ} \mathrm{C}$ and $300{ }^{\circ} \mathrm{C}$ to $2000{ }^{\circ} \mathrm{C}$ with an accuracy of $\pm 2^{\circ} \mathrm{C}$ or $\pm 2 \%$, whichever is greater. The temperature range is important in this application since, when exposed to temperatures exceeding the camera's range, a pixel will saturate and no more information can be obtained. It means the camera will give useful data only if in correct temperature range, which needs to be changed manually during measurements.. With the camera characteristics, optics used and the distance of the camera from the specimens, the measured area on the specimen was $8 \times 8 \mathrm{~cm}$. The relation between thermogram pixel size and real distances, 
the emissivity of the source, and expression of the radiation view factor are necessary for the heat flux density computation at the given distance from the heat source towards the camera position.

Three specimens were constructed according to BS 8414-1 (Fig. 1), where three different types of thermal insulation systems (Table 1) were erected on the brick wall i.e. combustible expanded polystyrene (EPS) and non-combustible mineral wool (MW) insulation, respectively. The same rendering was used for all three specimens, i.e. organic rendering (acrylic render) was used. Insulation thickness was $15 \mathrm{~cm}$ for all three specimens, while on the insulation layer, reinforcing mesh together with render base coat and finishing coat were applied.
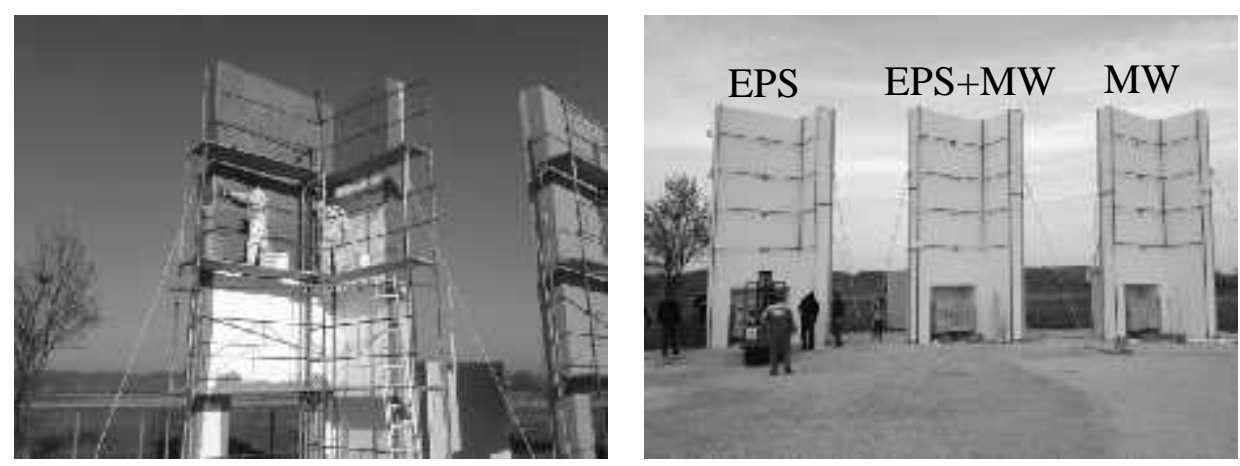

Fig. 1 Erecting the specimens (left), finished specimens (right)

Table 1 Description of the test specimens, ETICS system

\begin{tabular}{|c|c|c|c|}
\hline Specimen label & EPS & EPS+MW & MW \\
\hline $\begin{array}{c}\text { Specimen } \\
\text { description }\end{array}$ & $\begin{array}{c}\text { EPS insulation }+ \\
\text { organic render }\end{array}$ & $\begin{array}{c}\text { EPS insulation + organic render, fire } \\
\text { barrier above the openings }\end{array}$ & $\begin{array}{c}\text { MW insulation + } \\
\text { organic render }\end{array}$ \\
\hline $\begin{array}{c}\text { Reaction to fire } \\
\text { classification }\end{array}$ & B-s2,d0 & B-s2,d0 & A2-s1,d0 \\
\hline
\end{tabular}

All details regarding the specimen erection were published elsewhere (Banjad Pečur et al., 2015). Measurement of the temperature change with thermocouples was performed according to BS 8414 on all three specimens, by using Type $\mathrm{K}$ thermocouples, 1 and $3 \mathrm{~mm}$ of nominal diameter with insulated junctions, as well as plate thermometers. The ambient temperature at the start of the tests was within the range $20.5-22.2^{\circ} \mathrm{C}$. The air velocity in any direction was $2.2-4.5 \mathrm{~m} / \mathrm{s}$ during the test. Plate thermometers (PT) were placed $1 \mathrm{~cm}$ from the surface of the facades and pointing outwards, on two different heights from the top of the combustion chamber on each specimen, i.e. $1.25 \mathrm{~m}$ and $2.5 \mathrm{~m}$. External thermocouples were placed $5 \mathrm{~cm}$ from the face of the rendering at the same heights, while internal thermocouples were placed in the middle of the insulation layer, 100 and $300 \mathrm{~cm}$ from the top of the combustion chamber, respectively. The long-wave spectral range of the IR camera doesn't make it possible to look through smoke (visible on the thermogram - Fig. 2) and small sized particles and droplets, thus the transmissivity of smoke has to be taken into account.
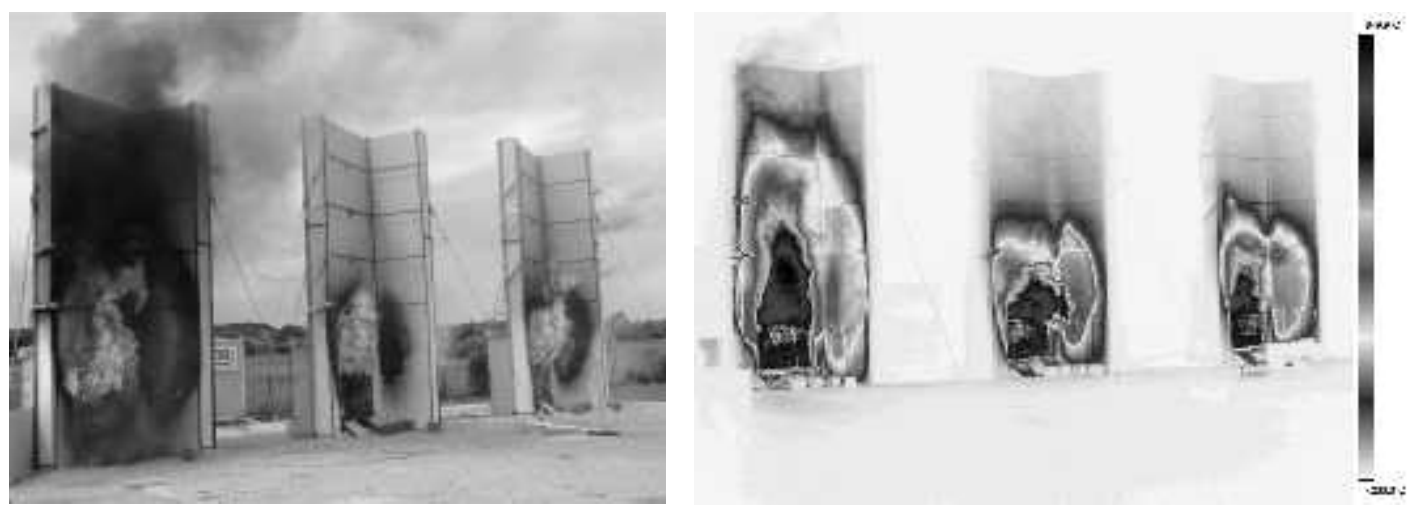

Fig. 2 Photography (left) and thermogram (right) of the tested specimens 
For an accurate IR measurement, the emissivity of the measured object is an essential quantity for correct temperature evaluation. The flame total emission consists of soot and gas emission components where the soot emits in a continuous spectrum, while the gasses emit in wavelength bands at specific spectral regions, which are given by chemical reactions during burning. It is not possible to determine the radiation at separated wavelength bands using the IR camera (Švantner et al., 2012). Moreover, the bolometric-type IR camera can detect radiation in wavelength interval from 7.5 to $13 \mathrm{~m}$. Additionally, during the test, the flame pulsated and the flame shape was changing significantly, due to the wind and the combustion dynamics.

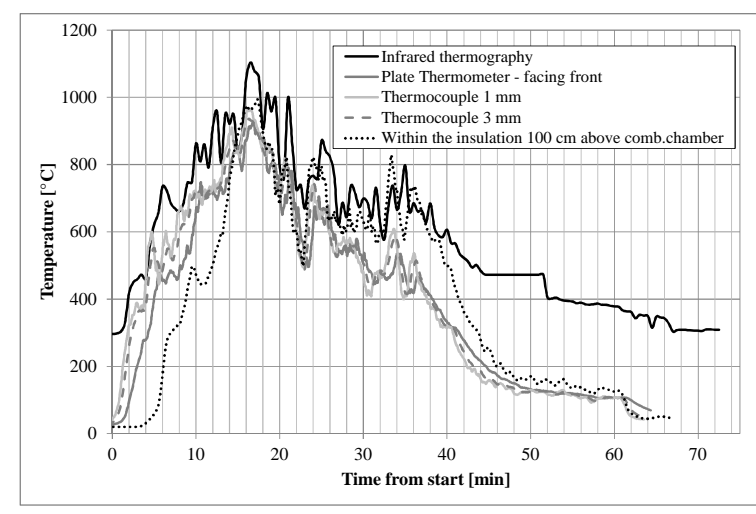

Fig. 3 Temperature at $125 \mathrm{~cm}$ above combustion chamber - EPS

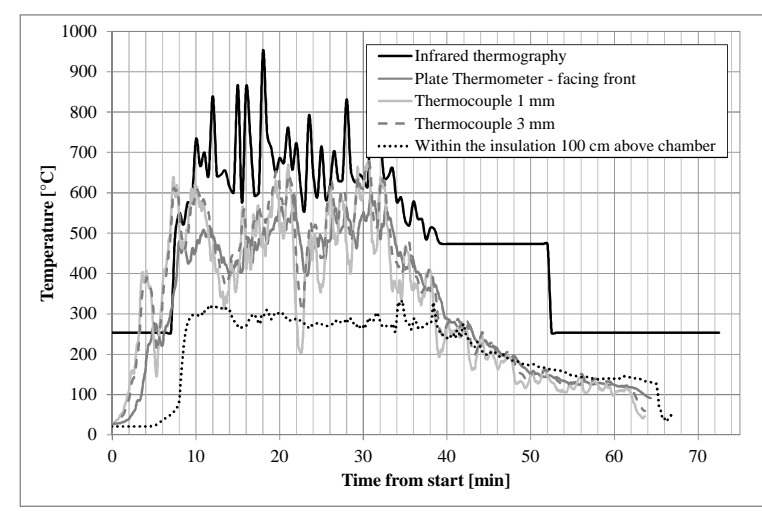

Fig. 5 Temperature at $125 \mathrm{~cm}$ above combustion chamber - EPS+MW

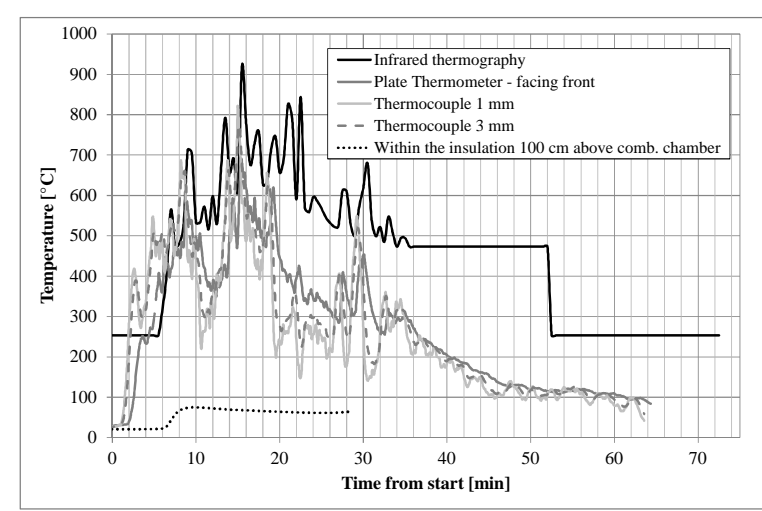

Fig. 7 Temperature at $125 \mathrm{~cm}$ above combustion chamber - MW

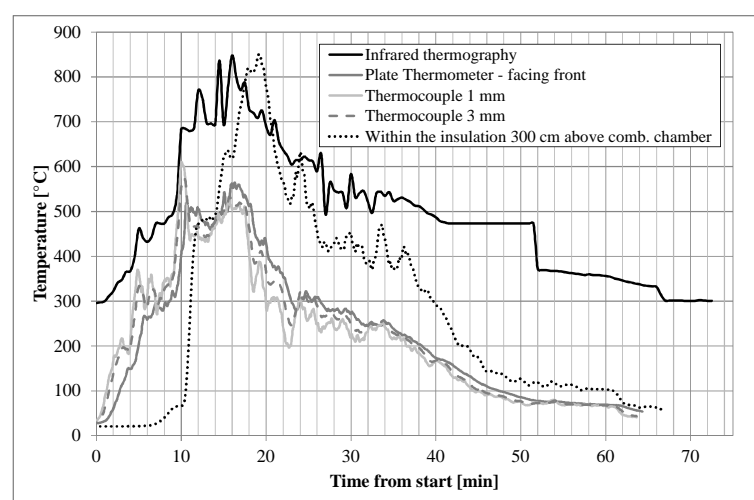

Fig. 4 Temperature at $250 \mathrm{~cm}$ above combustion chamber - EPS

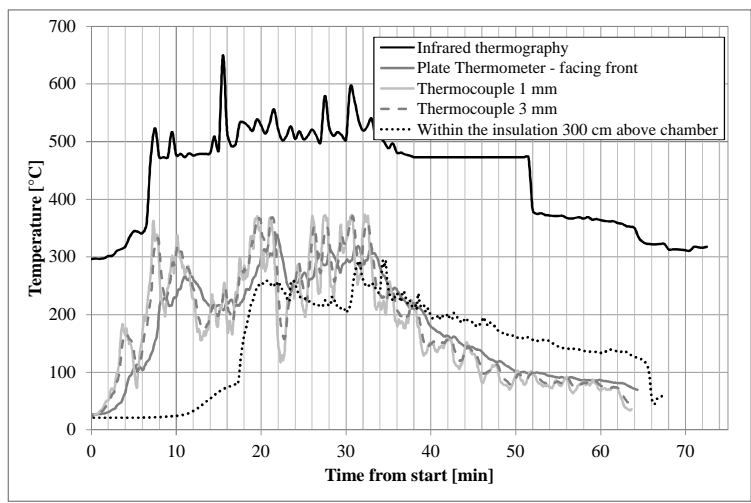

Fig. 6 Temperature at $250 \mathrm{~cm}$ above combustion chamber - EPS+MW

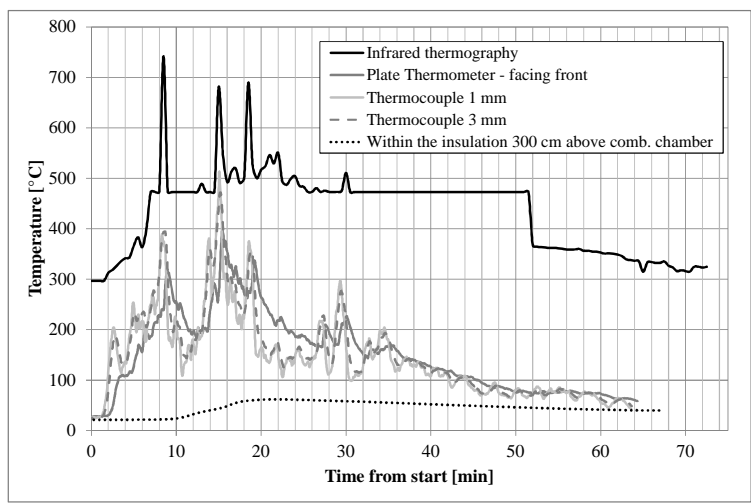

Fig. 8 Temperature at $250 \mathrm{~cm}$ above combustion chamber - MW

For the reasons explained above, a time averaged emissivity was therefore used in this paper. It was assumed in this research that the measured object would behave as a gray body. This is the essential 
simplification that allows an application of IR camera for temperature measurement in façade fire tests, and this assumption also limits the use of the results since the assumptions and simplifications used brought some measurement uncertainty. In this paper, the emissivity used was $\varepsilon=0.95$.

The measurement result is a time sequence of thermographs - the temperature map pictures of the size $640 \times 480$ pixels (Fig. 2), from which the temperature change of specific pixels were extracted in order to get their temperature evolution in time, as presented in Fig. 3 to Fig. 8. In Fig. 3 to Fig. 8 temperature evolution curves that were collected using IR thermography have flat parts, because the detector was exposed to temperatures exceeding the camera's range, and pixels were saturated thus no more information could be obtained.

\section{RESULTS AND DISCUSSION}

It is evident that temperatures measured on the specimens 125 and $250 \mathrm{~cm}$ above the combustion chamber are significantly higher than temperatures measured using both plate thermometers and external thermocouples. This is due to few issues related to the measurement accuracy and thus errors related to both measurement procedures. First is the fact that using IR thermography it wasn't pure specimen's temperature that was measured, but rather the "burning specimens" i.e. the radiation of a mixture of flames, combustion products, and specimens themselves (organic render and insulation materials) at the same time. The emissivity of flames, soot, and specimen was assumed to be 0.95 but even though slight changes in emissivity don't influence the results significantly, this should be investigated further. Additionally, flames emit IR radiation at different intensities at different wavelengths and at certain wavelengths in the IR spectrum flames emit hardly any thermal radiation at all, since in this research only the LWIR spectral band was considered, it has to be assumed that much of energy was not even detected. During the test presented in this paper, typical flames were turbulent and they had an intense luminosity due to their great amount of soot. Changes in wind velocity and direction and in fuel distribution determine the supply of air in the combustion and thus its efficiency, causing the emissivity change, i.e. appearance of flames with higher or lower emissivities.

The second problem would be that of the thermocouples and heat losses due to convective and radiation cooling of the thermocouples which also need to be assumed. Both convective and radiation losses influence the thermocouple measurement results, since the cooling heat flux increases with the increase of the temperature of the target object. In practice this means that the heat energy that sensor absorbs from the medium is being transferred by means of convection and radiation to the surroundings instead of being conducted to the sensor. For example (Ametek, 2007) reports that errors due to radiation exchange can be pretty significant, i.e. in an incinerator with a temperature of approx. $850^{\circ} \mathrm{C}$ and a wall temperature of approx. $250^{\circ} \mathrm{C}$, the measuring errors may be as high as $50^{\circ} \mathrm{C}$. This can clearly be seen if temperatures measured with IR camera are compared to the temperatures measured using internal thermocouples, where quite good comparison is evident. This is especially visible in Fig. 3 and Fig. 4 where EPS has melted behind the rendering layer and there is no obstruction for fire and/or smoke to heat up the thermocouples in question. The difference of IR measurements and those gained with internal thermocouples visible in Fig. 5 - Fig. 8 is due to the fact that MW fire barrier prevented the heat spread behind the rendering in EPS+MW specimen, like mineral wool prevented the heat spread in the MW specimen. Temperatures within the insulation layer of the EPS specimen (Fig. 3 and Fig. 4) are significantly higher than those measured using the external thermocouples positioned in front of the rendering where they are subjected to the effect of wind and radiation to much colder environment.

\section{CONCLUSIONS}

The assumptions and simplifications used brought some measurement uncertainty as described in previous chapter, however the measurement was prepared very quickly and with minimal additional expenses. The IR thermography allows a continuous evaluation of the whole $2 \mathrm{D}$ temperature field across the specimens in time. Disadvantages of this measurement method result from the used assumptions and IR camera measurement principles and its limitations. In general, an IR camera 
has to be placed at a safe distance from the measured heat source, while at the same time the heat source should be fully visible by the IR camera. The assumptions for the radiation properties of the measured object can also not be generalized since they are affected by several factors, including the flame thickness, the fuel source, the amount of air in the combustion, the amount of soot as well as the amount of smoke, its composition and concentration, etc. The results are based on some simplifications, and concerning the intended application and established failure criteria it is not completely clear how much these assumptions are satisfied, since thermocouple measurements are also influenced by external conditions, and do not show real temperature of the facade. Although presented IR measurement has some limitations, it is suitable for depicting the 2D temperature field change across the whole specimen. Additionally, IR thermography could be used for determining the extent of damage behind the rendering, as well as the flame height. It has been shown in the paper that external thermocouple measurements are influenced by convection and radiation heat losses and that they underestimate the temperature measurements, while IR measurements give temperatures that are similar to those gained by thermocouples within the insulation layer. Further research is needed to try to connect the measurements with numerical prediction models.

\section{ACKNOWLEDGMENTS}

The authors would like to thank for the support during the research to Fire Safe Europe and Croatian Association for Fire Protection, SP Technical Research Institute of Sweden, Slovenian National Building and Civil Engineering Institute ZAG, Laboratory for thermal measurements LTM, Faculty of Civil Engineering, University of Zagreb, as well as to the donors of the materials.

\section{REFERENCES}

AMETEK Calibration Instruments, 2007. Industrial temperature measurement, Allerød, Denmark

Arakawa A., Saito K., Gruver W. A., 1993. Automated Infrared Imaging Temperature Measurement with Application to Upward Flame Spread Studies", Combustion and Flame; 92 (3), p. 222-230.

Banjad Pecur I., Bjegović D., Boström L., Milovanović B., Hajduković M., 2015. ETICS Fire Performance test, Fifth International Workshop on Performance, Protection \& Strengthening of Structures under Extreme Loading, June 28-30, 2015, East Lansing, MI, USA (accepted for publishing)

Chatris J.M., 2002. Velocitat de combustió i distribució de temperatures en incendis de bassals d'hidrocarburs, $\mathrm{PhD}$ thesis, Escola Tècnica Superior d'Enginyeria Industrial de Barcelona, Universitat Politècnica de Catalunya, Barcelona, Spain.

Drysdale, D., 1997. An introduction to fire dynamics. New York: John Wiley and Sons.

de Vries J., Ren N., Chaos M., 2015. Temperature measurements on solid surfaces in rack-storage fires using IR thermography, Proc. SPIE 9485, Thermosense XXXVII, May 12, 2015, Baltimore, MD, USA

Du J.C., Huang Q.X., Yan J.H., 2012. Method for determining effective flame emissivity in a rotary kiln incinerator burning solid waste, Journal of Zhejiang University-SCIENCE A (Applied Physics \& Engineering), 13(12), p. 969-978.

Hagglund B., Persson L.E., 1976. An experimental study of the radiation from wood flames, FoU-Brand

Meléndez J., Foronda A., Aranda J. M., López F., López del Cerro F. J., 2010. Infrared thermography of solid surfaces under fire, in QIRT 10, July 27-30, 2010, Québec, Canada.

Meléndez J., Aranda J. M., de Castro A. J., F. López., 2006. Measurement of forest fire parameters with multispectral imaging in the medium infrared, QIRT Journal; vol. 3, p. 183-200.

Jiang, F.H., 1995. Prediction of Flame Radiation and Temperature in Polymer Combustion, Proceedings of the asia-oceania symposium on fire science \& technology AOFST 2,

Pastor E., Rigueiro A., Zárate L., Giménez A., Arnaldos J., Planas E., 2002. Experimental methodology for characterizing flame emissivity of small scale forest fires using infrared thermography techniques, Forest Fire Research \& Wildland Fire Safety, Viegas (ed.), Rotterdam, Millpress.

Rasbash D.J., Rogowski Z.W., Stark G.W.V., 1956. Properties of fires of liquids. Fuel, 31, p. 94-107.

Quian C., Saito K. 1995. Measurements of pool-fire temperature using IR technique, Combustion Fundamentals and Applications Proceedings, April 23-26, 1995, San Antonio, TX, USA, p. 81-86.

Sato T., Kunitomo T., Yoshii S., Hashimoto T., 1969. On the monochromatic distribution of the radiation from the luminous flame, Bulletin of Japan Society of Mechanical Engineers, 12(53).

Švantner M., Vacikova P., Honner M., 2012. IR thermography heat flux measurement in fire safety applications, Infrared Physics \& Technology 55(4), p. 292-298. 